\title{
Effect of Turning Frequency on Maturity during Kitchen Waste Composting
}

\author{
Yudong Zhang ${ }^{1,2, ~ a, ~ H o n g y u ~ Z h a n g ~}{ }^{1, b^{*}}$, Jun $^{1} u^{1, c}$, Jihong Wang ${ }^{2, d}$
}

1. Beijing Building Materirals Academy of Science Research/State Key Laboratory of Solid Waste Reuse for Building Material, Beijing100041, China;

2.College of Resource and Environment Science, Jilin Agricultural University, Jilin 130118, China;

azyd_chq@126.comb ${ }^{\mathrm{b}}$ zhyycj6688@163.com, ${ }^{\mathrm{c}}$ gujun@bbma.com.cn, ${ }^{\mathrm{d}}$ wjh489@126.com

Keywords: Kitchen waste; Aeration pattern; Composting; Maturity

Abstract. In order to determine the effectiveness of turning frequency in maturity in kitchen waste composting process. Four treatments by setting up different turning frequency which are twice a week, once a week, once every two weeks and never turning were conducted during kitchen waste compositing with corn straw as compost amendment. Temperature, $\mathrm{O}_{2}$, GI, EC, pH were carried out as indexes. Results show that these treatments met the Chinese standard for 5-7days for sanitation except the treatment of never turned compost material. Only the treatment with turned material once a week up to the standard of maturity during co-composting completely; however, the treatment with turned compost material twice a week and never turned compost material are up to the standard of harmless only. Comprehensive above results, turn compost material once a week is the best turning frequency for kitchen waste composting.

\section{Introduction}

Methods of household waste aerobic composting mainly include natural ventilation, turns material regularly and forced draft ${ }^{[1]}$.Turns material regularly is a method that turn the compost material with plan, so that $\mathrm{O}_{2}$ could add into compost body during turning compost materials, plenty $\mathrm{O}_{2}$ is conducive decomposition of organic matter by microbial, accelerate the process of compost. Turning material could promote compost material mixing and promote the evaporation of compost material. Researchers did many studies in this filed. Hua Dangling et al. carried out experiments to investigate the effect of turning frequency and covering on manure-straw compost which had different turning frequency, the results show that non-covering with turning once two weeks is the optimum scheme for pig manure-straw composting ${ }^{[2]}$. Liu et al studied the effect of turning frequency on quantitative reduction during compost agroforestry waste and restaurant garbage, finding that treatment turning every 4 days had the best maturity ${ }^{[3]}$.

\section{Materials and methods}

Raw materials and treatments design. The mixed household waste (with the size among 15-80 $\mathrm{mm}$ ) used in this experiment was collected from Ma Jia-lou pre-sorting station in Beijing. In this study, four group experiments were conducted with turning frequency, the treatments design as below.

Table 1 Design of experiment

\begin{tabular}{ccccc}
\hline Item & T1 & T2 & T3 & T4 \\
\hline Turning frequency & Twice a week & Once a week & Once two weeks & Never \\
\hline
\end{tabular}

The composting cycle is 30 days. Turns heaps and sampling time are $0 \mathrm{~d}, 3 \mathrm{~d}, 7 \mathrm{~d}, 14 \mathrm{~d}, 21 \mathrm{~d}$ and $30 \mathrm{~d}$, turn out all material and fully blending, take $500 \mathrm{~g}$ for solid indexes determination follow-up. Then 
put material back into the fermentation tanks continue composting experiment.

Analysis method. Composting temperature recorded by the temperature automatic monitoring system, directly read by computer. Germination index (GI) is used fresh samples extraction liquor in deionized water, solid-liquid ratio is $1: 10$, take $9 \mathrm{ml}$ extraction liquor in a petri dish with a filter paper, put 10 seeds in it then placed in a incubator with the temperature of $(20 \pm 1){ }^{\circ} \mathrm{C}$, cultivate $48 \mathrm{~h}$. The moisture content was determined by drying the samples at $105^{\circ} \mathrm{C}$ until the weight was constant. Electrical conductivity (EC) and hydrogen ion concentration $(\mathrm{pH})$ use a Portable multi-parameter measurement instrument to determination its extraction liquor.

\section{Results and discussion}

Change of temperature. Temperature is reactor in the process of the heat produced by microbial metabolism and biochemical activity characteristics during composting ${ }^{[4]}$. It is can be see in Fig.1, temperature of four treatments (T1,T2,T3 and T4) can divided into temperature rising period, thermophilic phase, cooling phase and stable phase. The thermophilic phase $\left(>55^{\circ} \mathrm{C}\right)$ of $\mathrm{T} 1$ lasted 7 days, which is the treatment with twice turning per week, this kind of turning frequency could add enough $\mathrm{O}_{2}$ in the material, result in the microbial decomposition of organic matter, reach a high temperature than other treatments, frequent turned material also resulted in heat of $\mathrm{T} 1$ treatment lost faster, so the thermophilic phase of T1 last shorter. The thermophilic phase of T2 lasted for 11 days, which turning frequency is once a week. Oxygen supplement of this kind of turning frequency is appropriate, have a benefit to microbial decomposition of organic matter in composting material, prompting the temperature of compost material rising, moreover this turning frequency makes the temperature loss less, make thermophilic phase is longer. Thermophilic phase of T3 and T4 lasted 8 and 4 days only, respectively. Except T4, other treatments with different turning frequency were all met the Chinese standard of $>55^{\circ} \mathrm{C}$ for $5-7$ days for sanitation ${ }^{[5]}$.Four treatments all met cooling phase in 16th, and approach ambient temperature gradually. In addition to T4, other 3 treatments met the Chinese standard. We can see from results above, turning frequency appropriate not only promote the decomposition of organic matter, but also can reach harmless result. Turning low-frequency and turning frequently have a disadvantage of composting, and turning frequently would increase the labor farce and power of compost.

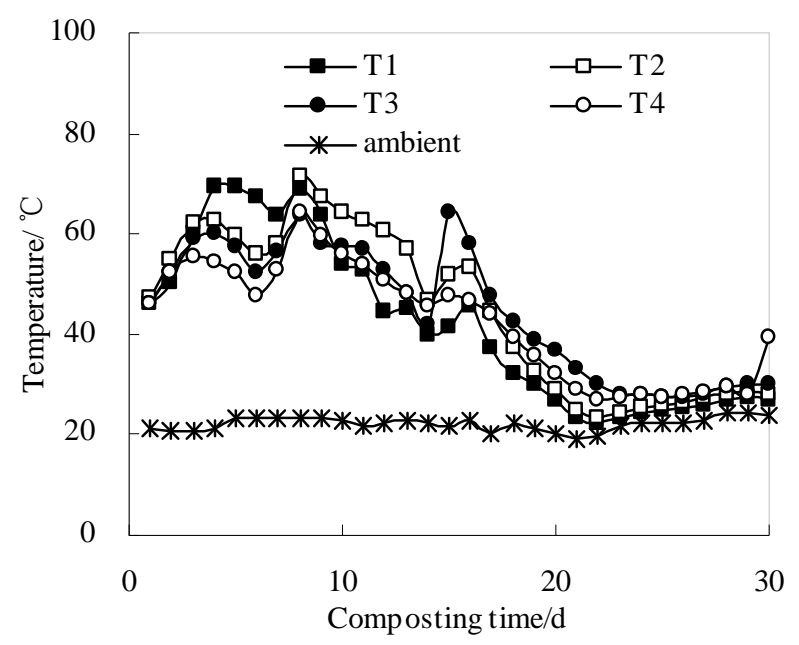

Fig.1 Change of Temperature for different treatments during composing

Change of $\mathrm{O}_{2}$ content. Outlet $\mathrm{O}_{2}$ concentration reflect the activity of microbial in aerobic compost, also is the symbol of decomposition degree of organic matter ${ }^{[6]}$. The changes of outlet $\mathrm{O}_{2}$ concentration were shown in Fig 2. Change of $\mathrm{O}_{2}$ concentration of $\mathrm{T} 1$ and $\mathrm{T} 2$ are similarity, all 
have a brief drop in $4^{\text {th }}$ and $8^{\text {th }}$ days. Change of $\mathrm{O}_{2}$ concentration of T3 and T4 are similarity, except $\mathrm{O}_{2}$ of $\mathrm{T} 3$ have a brief drop in $15^{\text {th }}$ day, and these two treatments all have a small drop and have a rising trend till the end of composting finish. Falling of $\mathrm{O}_{2}$ concentration is due to turning the compost material improve environment of compost body, microbial decompose organic matter accelerate. Similarity of T1 and T2 shows that turning twice per week have few impact of decomposition of organic matter.

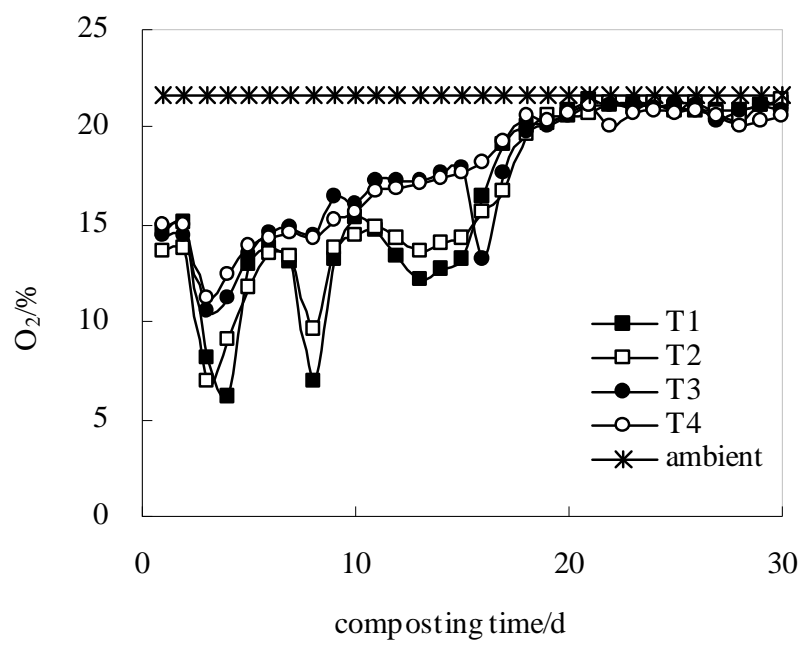

Fig.2 Change of $\mathrm{O}_{2}$ for different treatments during composing

Change of ph, GI and EC. Tab.1 is the changes of pH, GI and EC in initial and finish. Changes of $\mathrm{pH}$ are one of the most important indexes during compost. Appropriate $\mathrm{pH}$ can not only promote the rapid growth of microorganisms, increase the degradation rate of organic matter, but also can reduce the loss of ammonia nitrogen in the process of compost ${ }^{[7]}$.As shown in Tab. 2 of composting material initial $\mathrm{pH}$ is weak acidity (6.8). Along with proceed of composting, rising temperature lead to volatilization of organic acids and mineralization of organic nitrogen make $\mathrm{pH}$ rise up till to composting and stay at a higher level. The results of $\mathrm{pH}$ are alkalescency, met the request of compost safety standards $(7 \sim 8.5)^{[8]}$.

The most sensitivity index to evaluate composting maturity is GI, could be used to explain the general performance of its low-toxic (effects to root growth) and high-toxic (effects to sprout) ${ }^{[9]}$. As can be seen in Tab.1, GI of initial compost material is $1 \%$, along with proceed of composting, toxic substance which can be inhibit seeds sprout was decomposed persistently, GI of compost rise gradually, at the end of compost, GI of 4 treatments are $78.5 \%, 96 \%, 38.3 \%$ and $67.1 \%$ respectively. Neyla' researches showed that composting material be considered no toxic when GI is greater than $50 \%$, and be considered decomposed completely when GI is over than $80 \%{ }^{[9]}$. Turning frequency once a week adjust the porosity and oxygen content of compost material, provide a better environment for microorganism, prove the composite of toxic matter, lead to GI of final compost material more than $80 \%$. Turning frequency of T1, T3 and T4 have less contribution of organic material composite, toxic matter composite incomplete, T1 and T4 up to the standard of harmless only, T3 did not met the harmless standard.

Total ion concentration of compost material extraction liquor is reflected by $\mathrm{EC}$, one of requirements of composting maturity ${ }^{[10,11]}$. EC of compost product more than $4 \mathrm{mS} / \mathrm{cm}$ would have a negative effect for plants growth, such as low germination rate and wilting ${ }^{[12]}$. Changes of EC initial and final are shown in Tab1. EC of initial material is $2.1 \mathrm{mS} / \mathrm{cm}$. Along with the composting, Humification makes various salts and small organic molecules are fixed and turn into Macromolecular humic acid, make EC of compost material decline. At the end of composting, EC of four treatments all below $3 \mathrm{mS} / \mathrm{cm}$, in the range of crop growth security, can be ruled out for the 
toxicity of crops.

Table 2 changes of $\mathrm{pH}$, GI and EC

\begin{tabular}{ccccccc}
\hline \multirow{2}{*}{ Treatments } & \multicolumn{2}{c}{$\mathrm{pH}$} & \multicolumn{2}{c}{ GI $(\%)$} & \multicolumn{2}{c}{ EC $(\mathrm{mS} / \mathrm{cm})$} \\
\cline { 2 - 7 } & Initial & Finish & Initial & Finish & Initial & Finish \\
\hline T1 & 6.80 & 8.51 & 1.0 & 78.5 & 2.10 & 1.61 \\
T2 & 6.80 & 8.69 & 1.0 & 96.0 & 2.10 & 1.17 \\
T3 & 6.80 & 8.46 & 1.0 & 38.3 & 2.10 & 1.64 \\
T4 & 6.80 & 8.33 & 1.0 & 67.1 & 2.10 & 1.98 \\
\hline
\end{tabular}

\section{Conclusion}

(1) Except T4, other treatments with different turning frequency in ventilation of $3.3 \mathrm{~m}^{3} / \mathrm{m}^{3} \cdot \mathrm{h}$ (ventilate shutoff $20 \mathrm{~min}$ and turn on $40 \mathrm{~min}$ ) were all met the Chinese standard of $>55^{\circ} \mathrm{C}$ for $5-7$ days for sanitation (Chinese Standard DB11/T 272-2005).

(2) It can be seen from EC, $\mathrm{pH}$, all four treatments met the request of compost safety standards and can be ruled out for the toxicity of crops.

(3) It can be seen from GI, only the treatment with turned material once a week up to the standard of maturity during co-composting completely, and the treatment with turned compost material twice a week and never turned compost material are up to the standard of harmless only.

(4) Comprehensive the views above, under the condition of four experiments, turn compost material once a week is the best turning frequency for kitchen waste composting in 30 days.

\section{Acknowledgements}

This study was financially supported by Beijing Natural Science Foundation (NO.8144050), and supported by the country "12th Five-Year Plan" to support science and technology projects (2012BAC15B04), the work also funded by the national "863 Plan" project (2013AA031602).

\section{References}

[1] Y.H. Li, L. Liao, Aeration system design of MSW aerobic composting J. Environmental sanitation engineering, 12(2004)20-22.

[2] D.L. Hua, F. Liu, G.X. Li, et al. Effect of turning and covering techniques on pig manure-straw composting. J. Transactions of CSAE, 27(2011) 210-216.

[3] F. Li, J.H. Chen, L. Wang, et al. Effects of different turning frequency on reduction, humification and stabilization of composting J. Industrial microbiology, 44(2014)6-12.

[4] Y.Q. Wang, F. Schuchardt, H. Chen, et al. effects of turning frequency on chemical and physical properties in windrow composting of spent Chinese herbal medicine J. Chinese agricultural science bulletin, 29(2012)247-252.

[5] Chinese Standard DB11/T 272-2005.

[6] G. Eftoda, D. Mccartney. Determining the critical bulking agent requirement for municipal biosolids composting J. Compost Science \& Utilization, 12(2004)208-218.

[7] R.H. Yuan, X.Y. Peng, Z.S. Wu, et al. study on maturity of municipal solid waste compost. J. Journal of Chongqing jianzhu university,25(2003)54-58.

[8] M. Masó, A. Blasi. Evaluation of composting as a strategy for managing organic wastes from a municipal market in Nicaragua J. Bioresource Technology, 99(2008)5120-5124.

[9] S. Neyla, K. Soulwene, M. Fadhel, et al. Microbiological parameters and maturity degree during composting of Posidonia oceanica residues mixed with vegetable wastes in semi-arid pedo-climatic 
condition J. Journal of Environmental Science, 21(2009)1452-1458.

[10] G. Eftoda, D. Mccartney. Determining the critical bulking agent requirement for municipal biosolids composting J. Compost Science \& Utilization, 12(2004)208-218.

[11] Y.M. Yang, H.L. Liu, Z.F. Yang, et al. Methods and techniques in the control of nitrogen loss during the composting: A review J. Journal of Beijing Normal University (Natural Science), 41(2005)213-216.

[12] C.P. Li. G.X. Li, Y.C. Li, et al. Fuzzy mathematics-based evaluation of municipal solid waste compost maturities in different spaces in static tunnel from Nangong compost plant J. Transactions of the CSAE,23(2007)201-206. 